\title{
A functional genomic screen in Saccharomyces cerevisiae reveals divergent mechanisms of resistance to different alkylphosphocholine chemotherapeutic agents.
}

Jacquelin M. Garcia*, ${ }^{*}$, Michael J. Schwabe ${ }^{*}, 4$, Dennis R. Voelker ${ }^{\dagger}$, and Wayne R. Riekhof

*School of Biological Sciences, University of Nebraska - Lincoln, Lincoln, NE, USA; tDepartment of Medicine, National Jewish Health, Denver, CO, USA

Current address: ${ }^{3}$ Division of Biology and Biomedical Sciences, Washington University, St. Louis, MO, USA; ${ }^{4}$ Department of Surgery, Creighton University School of Medicine, Omaha, NE, USA 


\section{Abstract}

The alkylphosphocholine (APC) class of antineoplastic and antiprotozoal drugs, such as edelfosine and miltefosine, are structural mimics of lyso-phosphatidylcholine (lyso-PC), and are inhibitory to the yeast Saccharomyces cerevisiae at low micromolar concentrations. Cytotoxic effects related to inhibition of phospholipid synthesis, induction of an unfolded protein response, inhibition of oxidative phosphorylation, and disruption of lipid rafts have been attributed to members of this drug class, however the molecular mechanisms of action of these drugs remain incompletely understood. Cytostatic and cytotoxic effects of the alkylphosphocholines exhibit variability with regard to chemical structure, leading to differences in effectiveness against different organisms or cell types. We now report the comprehensive identification of Saccharomyces cerevisiae titratableessential gene and haploid non-essential gene deletion mutants that are resistant to the APC drug miltefosine (hexadecyl-O-phosphocholine). 58 strains out of $\sim 5600$ tested displayed robust and reproducible resistance to miltefosine. This gene set was heavily enriched in functions associated with vesicular transport steps, especially those involving endocytosis and retrograde transport of endosome derived vesicles to the Golgi or vacuole, suggesting a role for these trafficking pathways in transport of miltefosine to potential sites of action in the endoplasmic reticulum (ER) and mitochondrion. In addition, we identified mutants with defects in phosphatidylinositol-4-phosphate synthesis (TetO::STT4) and hydrolysis (sac14), an oxysterol binding protein homolog (osh2 $\Delta$ ), a number of ER resident proteins, and multiple components of the eisosome. These findings suggest that ER-plasma membrane contact sites and retrograde vesicle transport 
bioRxiv preprint doi: https://doi.org/10.1101/2020.10.16.343244; this version posted October 17,2020 . The copyright holder for this preprint (which was not certified by peer review) is the author/funder, who has granted bioRxiv a license to display the preprint in perpetuity. It is made available under aCC-BY 4.0 International license.

are involved in the interorganelle transport of lyso-PtdCho and related lyso-phospholipid-

like analogs to their intracellular sites of cytotoxic activity. 


\section{Introduction}

The alkylphosphocholine (APC) class of drugs are structural analogs of lysophosphatidylcholine (lyso-PtdCho), and have been extensively investigated as antineoplastic agents (C. Gajate et al., 2012; Consuelo Gajate \& Mollinedo, 2014). They also act as effective anti-protozoal compounds, with potent activity against Leishmania spp. and other apicomplexan parasites (Saraiva et al. 2002; Santa-Rita et al. 2004; Verma et al. 2007; Aichelburg et al. 2008; Machado et al. 2010). L. donovanii has been investigated with regard to genetic mechanisms leading to drug resistance, and miltefosine-resistant strains have been identified in which a $\mathrm{P}_{4}$-ATPase (lipid flippase) at the plasma membrane is defective, and thus the resistant strain fails to import the toxic compound (Pérez-Victoria et al. 2006; Seifert et al. 2007; Weingärtner et al. 2010). The APC's are also active against fungal pathogens such as Candida albicans and Cryptococcus neoformans (Widmer et al. 2006; Vila et al. 2015), and the yeast Saccharomyces cerevisiae has served as a model for studies on drug resistance and elucidation of the molecular mechanism(s) of action of these drugs (Hanson et al. 2003; Cuesta-Marbán et al. 2013; Czyz et al. 2013). Although the body of work on APC resistance is extensive, particularly on mechanisms of action of edelfosine and miltefosine (Fig.1A), an understanding of the precise mechanism(s) of action of the APC's remains incomplete, and the intracellular location of targets and mechanisms of action of these drugs appear to vary from compound to compound and between organisms and cell types.

A main mechanism of drug resistance, however, is clearly attributable to the loss of active transport of the APC's into cells, which occurs via $\mathrm{P}_{4}$-family ATPase mediated 
internalization at the plasma membrane (Hanson et al. 2003; Riekhof and Voelker 2009). In the extensively studied $L$. donovanii system, disruption of the miltefosine transporter, LdMT (Pérez-Victoria et al. 2006; Seifert et al. 2007) or its non-catalytic $\beta$-subunit, LdRos3 (Pérez-Victoria et al. 2006) leads to drug resistance, similar to loss of the homologous S. cerevisiae proteins Dnf2p or Lem3p, respectively, which leads to edelfosine and miltefosine resistance in yeast (Hanson et al. 2003). A whole genome non-essential gene knockout screen for edelfosine resistant and hypersensitive mutants of $S$. cerevisiae was reported in a pair of studies (Cuesta-Marbán et al. 2013; Czyz et al. 2013). This work showed that edelfosine and miltefosine treatment causes loss of the proton efflux pump Pma1p from detergent resistant subdomains of the plasma membrane. This leads to an apparent mislocalization of Pma1p in APC treated cells, a corresponding defect in regulation of intracellular $\mathrm{pH}$, and increased sensitivity to low extracellular $\mathrm{pH}$. The edelfosine-resistant gene deletion mutant set these studies identified was enriched in genes encoding proteins with roles in endocytosis and endosomal transport, as well as in intracellular $\mathrm{pH}$ regulation.

We now report the comprehensive identification of miltefosine-resistant $S$. cerevisiae haploid deletion and titratable-essential gene strains. While there is overlap with the edelfosine-resistant mutant strains, we identified a substantial number of new mutant strains as miltefosine-resistant, suggesting that the mechanism(s) by which these compounds exert their cytotoxic effects are different, and that the mechanisms of fungal resistance to these drugs is not conserved across this drug class. Additionally, we identified an oxysterol-binding protein homolog (Osh2p) as being necessary for miltefosine sensitivity, and suggest that its presence at membrane contact sites is 
necessary for efficient APC dissemination to sites of action within the cell. We further show that proper Osh2p localization is likely to be dependent on the conent and localization of phosphatidylinositol-4-phosphate, as judged by mislocalization of Osh2pGFP in TetO::STT4 and sac1D strains.

\section{Materials and Methods}

Strains and growth conditions. All media components were from Fisher Scientific or Sigma-Aldrich. Routine growth and screening was conducted on YPD (1\% w/v yeast extract, $2 \% \mathrm{w} / \mathrm{v}$ peptone, $2 \% \mathrm{w} / \mathrm{v}$ glucose) or YPGro (2\% v/v glycerol instead of glucose) solidified with $1.5 \% \mathrm{w} / \mathrm{v}$ agar. Miltefosine was prepared as a $10 \mathrm{mg} / \mathrm{ml}$ stock solution in water, filter sterilized, and stored in frozen aliquots until just prior to use. Doxycycline was prepared as a $10 \mathrm{mM}$ stock solution in ethanol and added to media (10 $\mu \mathrm{M}$ final concentration) as needed.

The MATa deletion collection, constructed in parental strain BY4742 (BakerBrachmann et al. 1998), and the tetracycline-repressible essential gene collection, constructed in strain R1158 (Mnaimneh et al. 2004), were purchased from Invitrogen. Additional osh $1 \Delta, \operatorname{osh} 2 \Delta, \operatorname{osh} 3 \Delta$, and osh $1 \Delta$ osh2 $\Delta$ osh3 $\Delta$ strains in the SEY6210 background were provided by Tim Levine (University College London.) Initial screens were conducted by thawing 96-well glycerol stock plates, mixing with a stainless steel 96pin tool (Dan-Kar model MC-96; Fisher Scientific), and dilution into $150 \mu$ l of sterile YPD medium in a 96-well plate. Approximately $3 \mu \mathrm{l}$ of culture is transferred by each pin under these conditions, giving a $\sim 50$ fold dilution in the recipient plate. The diluted cultures were then pinned to solid YPD medium with or without $4 \mu \mathrm{g} / \mathrm{ml}(9.8 \mu \mathrm{M})$ miltefosine (Avanti 
Polar Lipids, Alabaster, AL, USA), incubated at $30{ }^{\circ} \mathrm{C}$ for up to 7 days, and visually monitored daily for growth of miltefosine-resistant patches. Cultures from the essential doxycycline-repressible ("Tet-off") promoter collection (Mnaimneh et al. 2004) were screened similarly, except that an additional series of plates were used for the screen, which included $10 \mu \mathrm{g} / \mathrm{ml}$ doxycycline to effect repression of the essential library gene, as previously described (Wishart et al. 2005).

Miltefosine-resistant strains were identified and subcultured for further studies. Resistant strains were colony-purified from patches on the uninhibited miltefosine-free YPD replica plates, and single colonies were picked and grown to saturation in YPD. A 10-fold dilution series was prepared in 96-well plates and pinned to YPD (4 $\mu \mathrm{g} / \mathrm{ml}$ miltefosine) or YPGro (1 $\mu \mathrm{g}$ or $4 \mu \mathrm{g} / \mathrm{ml}$ miltefosine) and growth assessed after 48 or $96 \mathrm{~h}$, respectively. Strains that showed reproducible miltefosine resistance were thus identified, and categorized based on degree of sensitivity with glucose or glycerol as carbon sources.

Bioinformatic analyses. Primary and secondary screening led to identification of 58 genes which, when deleted or repressed, led to a reproducible miltefosine-resistant growth phenotype. Gene ontology analysis was performed with YeastMine tools available at the Saccharomyces Genome Database website (www.yeastgenome.org), and gene set analysis was conducted with YeastNet version 3.0 at www.inetbio.org/yeastnet (Kim et al. 2014). 
Microscopy. Strain BY4742 and the isogenic sac1 $1:$ KanMX deletion strain were transformed to uracil prototrohy with plasmid pTS312, a URA3 CEN plasmid expressing a C-terminal GFP fusion of Osh2p, which was a gift of Christopher Beh (Simon Fraser University.) Cultures were grown overnight in SC -Ura and imaged on an Evos FL inverted microscope with GFP fluorescence cube.

\section{Results and Discussion}

Screening for miltefosine resistant strains identifies a network of 58 highly connected genes enriched in membrane and trafficking functions. Table 1 provides a list of the genes that were identified as showing reproducible resistance to $4 \mu \mathrm{g} / \mathrm{ml}$ miltefosine on YPD, and that rescreened as positive after colony purification of original stocks and assessment with a 5-fold serial dilution spot-test. Relevant molecular structures are shown in Fig, 1A. Fig. 2 shows a typical re-screening result for a subset of 6 mutants from the haploid MATa BY4742 based mutant collection. These initial results demonstrated that the miltefosine-resistance phenotype is tractable in the context of a genome-wide deletion screen conducted on solid medium. Figure 5 shows a result typical of the essential-gene Tet-off screening phenotype (TetO::STT4), in which we selected strains that showed robust growth in the presence of miltefosine when doxycycline was present (gene repressed), and weak or absent growth in its absence (gene expressed normally)

When screening mutant libraries for strains with alterations in a phenotype of interest, it is useful to assess whether the screen has identified mutants in a subset of genes with related functions, or whether the screen has identified a set of diverse genes 
with little in common with regard to function or localization. We approached this question by assessing the connectivity of the identified gene set with regard to systems-based epistasis screens, protein-protein interaction studies, and other measures, such as shared protein domain architectures and co-citation indices. We also analyzed the enrichment of gene ontology (GO) terms associated with the gene set. The method of assessment of connectivity makes use of receiver operating characteristic (ROC) curve analysis (McGary et al. 2007), in which the area under the ROC curve is assessed in relation to that expected for a randomly chosen subset of genes. The results of ROC analysis for our set of 58 genes is given in Fig. 3. This approach makes use of the YeastNet v3 database (Kim et al. 2014) to assess whether a set of genes are more connected to each other than they are to a random subset of the genome. This approach led us to discover that miltefosine resistance is a powerful selection for mutants in a subset of genes that are highly connected via genetic interactions, protein:protein interactions, and co-citation indices with one another, with a p-value of $8.3 \times 10^{-11}$. This means that that the chances of identifying a random set of genes with this level of connectivity are on the order of 1 in $10^{-10}$. As a control, we selected two random pools of 58 genes each and analyzed their connectivity by ROC analysis as for the miltefosineresistance gene set. As expected, these subsets of genes displayed no significant numbers of connections beyond that which would be expected from random chance.

A second method of gene set analysis was performed by assessing the enrichment of gene ontology (GO) terms as a measure of relatedness, and allowed us to identify molecular components and processes that are significantly over-represented in the miltefosine-resistant mutant collection. Table 2 provides a list of GO terms that are over- 
represented in the miltefosine-resistant gene set. As might be expected for a set of mutants with resistance to a membrane-perturbing agent, GO components and processes associated with membrane assembly, protein trafficking, and transport through the endomembrane system are highly enriched in this analysis.

\section{The miltefosine resistant gene deletion set shows little overlap with a previously} described edelfosine resistance screen. As noted in Figure 1, approximately 264 deletion mutant strains were previously identified as showing some degree of edelfosine resistance (Cuesta-Marbán et al. 2013; Czyz et al. 2013). Our current study identified 58 mutants showing resistance to miltefosine, and of those, only 10 mutants were shared between the edelfosine and miltefosine resistance sets, although this may be a slight underestimate given that the edelfosine resistance screen did not encompass the essential gene titratable-promoter collection. Figure 1C shows a composite genetic and physical interaction map of edelfosine-miltefosine resistant shared genes and their directly interacting partners in the miltefosine resistance set, and identifies the t-SNARE TLG2 as a key hub in the interaction diagram for the shared edelfosine-miltefosine resistant gene set.

A $\operatorname{tg} 2 \Delta$ strain was identified along with $d n f 2 \Delta$, lem $3 \Delta$, and other components of endosome-plasma membrane recycling in a screen for strains resistant to the lantibiotic peptide Ro 09-0198 (Takagi et al. 2012). This work also showed that an EGFP-tagged Dnf2p reporter was mislocalized in the $\operatorname{tg} 2 \Delta$ background, suggesting that the Ro-0198 sensitive phenotype of $\operatorname{tg} 2 \Delta$ is due to mislocalization of Dnf2p from the plasma membrane to endosomes. Disruption or mislocalization of this lipid flippase would thus result in the 
accumulation of phosphatidylethanolamine on the outer leaflet of the plasma membrane, which is the ligand for this cytolytic peptide. Taken together with our results, this suggests that localization and proper function of the Dnf2p-Lem3p complex is dependent on TIg2p and a small cadre of proteins to which it is functionally linked, and that the genes in the intersection of the Venn diagram of Fig. 1B and in the interaction diagram of Fig. 1C encompass the core components necessary for flippase function, activity, and localization at the plasma membrane. We thus propose that while the core components of lysophospholipid uptake (the flippase core components and factors regulating its proper localization and function) are broadly conserved as determinants of APC sensitivity, individual members of this this drug class exert their cytotoxic effects by interacting with multiple and variable intracellular targets after their import via the flippase.

\section{Disruption of phosphatidylinositol-4-phosphate homeostasis and the oxysterol-} binding protein homolog Osh2p alters miltefosine sensitivity. The proteins disrupted in a subset of functionally related miltefosine-resistant mutants (osh $2 \Delta$, sac1 $1 \Delta$, and TetO::STT4) are involved in the function and localization of the oxysterol binding protein homolog Osh2p. Osh2p contains an oxysterol-binding domain at its C-terminus as well as several protein-protein and protein:lipid interaction motifs at its $\mathrm{N}$-terminus. These interaction motifs include Anykyrin-repeats which are likely to interact with other, currently unidentified, proteins (Beh et al. 2001), a Pleckstrin-homology (PH) domain that interacts with Ptdlns-4-P (Roy and Levine 2004), and a "two phenylalanines in an acidic tract" (FFAT) motif which interacts with the ER resident proteins Scs2p and Scs22p (Loewen et al. 2003; Kaiser et al. 2005; Loewen and Levine 2005). 
The phosphatidylinositol (Ptdlns) 4-kinase Stt4p (Yoshida et al. 1994; Cutler et al. 1997) generates Ptdlns-4-P at the plasma membrane (Foti et al. 2001; Baird et al. 2008), and is involved in actin polymerization and endocytosis, as well as in transport of PtdSer from the ER to the site of Psd2p (Trotter et al. 1998). The pool of Ptdlns-4-P generated by Stt4p is degraded by the phosphoinositide phosphatase Sac1p (Foti et al. 2001), which has additional functions in lipid trafficking and metabolism (Guo et al. 1999; Rivas et al. 1999; Hughes et al. 2000; Tahirovic et al. 2005; Riekhof et al. 2014; Tani and Kuge 2014). The strains sac1 $1 \Delta$, osh2 $\Delta$, and TetO::STT4 were all identified as miltefosine resistant (Figs. 4 and 5), suggesting that the Ptdlns-4-P cycle governed by Stt4p and Sac1p might be involved in the proper localization of Osh2p, and that mislocalization of Osh2p might lead to a defect in miltefosine uptake and distribution to intracellular targets. This idea was tested by expressing a GFP-tagged form of Osh2p in a wild-type and sac1 $\Delta$ background. As shown in Fig. 6, Osh2p in the wild type is localized in a punctate pattern at the cell periphery, while in the sac1 $1 \Delta$ mutant Osh2p is localized to intracellular structures and absent from the cell periphery.

Summary. Previous studies in S. cerevisiae (Cuesta-Marbán et al. 2013; Czyz et al. 2013) have identified a subset of genes that, when deleted, confer resistance to the APC analog edelfosine. While members of this drug class share superficial similarities to lysophosphatidylcholine in their structures, it has remained an open question as to the degree of overlap in their mechanisms of action. Our current work identifies the plasma membrane flippase Dnf2p and factors required for its correct localization and function as being shared between edelfosine, miltefosine and likely other members of this drug class with regard to the specific and active transport of the compounds into the cell. However, 
unlike the edelfosine studies, we did not identify factors that regulate intracellular $\mathrm{pH}$ or alter the function of the plasma membrane proton pump Pma1p as having a role in altered miltefosine sensitivity. We did however identify a new subset of genes as determinants of wild-type miltefosine sensitivity, and chose to assess the roles of the Ptdlns-4-P cycle and Osh2 localization in more detail. One interpretation of this data is that after the initial "flip" across the plasma membrane by Dnf2p/Lem3, miltefosine is transported to one or more sites of cytotoxic activity by non-vesicular transport routes that are dependent on the proper localization of the oxysterol-binding protein homolog Osh2p. Future work on this and other clusters of genes identified in this screen will provide additional insight into the mechanism(s) of action of miltefosine and other members of the APC drug class. 


\begin{tabular}{|c|c|c|c|}
\hline Gene ID & Name & Previous ID? & Description \\
\hline YAL009W & SPO7 & Yes & Subunit of Nem1p-Spo7p phosphatase holoenzyme \\
\hline YAL039C & CYC3 & No & Cytochrome c heme lyase \\
\hline YBR097W & VPS15 & No & Protein kinase involved in vacuolar protein sorting \\
\hline YBR184W & & No & Putative protein of unknown function \\
\hline YCR009C & RVS161 & No & Amphiphysin-like lipid raft protein \\
\hline YCR067C & SED4 & No & ER-protein that stimulates Sar1p GTPase activity \\
\hline YDL019C & $\mathrm{OSH} 2$ & No & Oxysterol-binding protein homolog family member \\
\hline YDR027C & VPS54 & No & Golgi-associated retrograde protein complex \\
\hline YDR028C & REG1 & No & Subunit of type 1 protein phosphatase Glc7p \\
\hline YDR093W & DNF2 & Yes & Aminophospholipid translocase (flippase) \\
\hline YDR095C & & No & Dubious ORF overlapping DNF2 \\
\hline YDR097C & MSH6 & No & Required for mismatch repair in mitosis and meiosis \\
\hline YDR126W & SWF1 & Yes & Palmitoyltransferase of SNARE proteins \\
\hline YDR323C & PEP7 & No & Vesicle-mediated vacuolar protein sorting \\
\hline YDR472W & TRS31 & No & Transport protein particle (TRAPP) I-III \\
\hline YER031C & YPT31 & No & Rab family GTPase \\
\hline YFL047W & RGD2 & No & GTPase-activating protein for Cdc42p and Rho5p \\
\hline YGL012W & ERG4 & No & C-24(28) sterol reductase \\
\hline YGL054C & ERV14 & No & COPII-coated vesicle protein \\
\hline YGL095C & VPS45 & No & Protein of the Sec1p/Munc-18 family \\
\hline YGL106W & MLC1 & No & Essential light chain for Myo1p \\
\hline YGL158W & RCK1 & No & Protein kinase involved in oxidative stress response \\
\hline YGR086C & PIL1 & No & Eisosome core component \\
\hline YGR141W & VPS62 & No & Vacuolar protein sorting (VPS) protein \\
\hline YHL028W & WSC4 & No & Endoplasmic reticulum (ER) membrane protein \\
\hline
\end{tabular}




\begin{tabular}{|c|c|c|c|}
\hline YHL031C & GOS1 & No & v-SNARE protein involved in Golgi transport \\
\hline YHR012W & VPS29 & Yes & Subunit of retromer complex \\
\hline YHR108W & GGA2 & No & Regulates Arf1p, Arf2p to facilitate Golgi trafficking \\
\hline YJL154C & VPS35 & Yes & Endosomal subunit of retromer complex \\
\hline YKL212W & SAC1 & No & Ptdlns-4-phosphate phosphatase \\
\hline YKR001C & VPS1 & Yes & Dynamin-like GTPase required for vacuolar sorting \\
\hline YKR019C & IRS4 & No & EH domain-containing protein \\
\hline YKR020W & VPS51 & No & Golgi-associated retrograde protein complex \\
\hline YKR068C & BET3 & No & Transport protein particle (TRAPP) complexes I-III \\
\hline YLR039C & RIC1 & No & Retrograde transport to the cis-Golgi network \\
\hline YLR082C & SRL2 & No & Protein of unknown function \\
\hline YLR093C & NYV1 & No & v-SNARE component of vacuolar membrane \\
\hline YLR305C & STT4 & No & Phosphatidylinositol-4-kinase \\
\hline YLR360W & VPS38 & No & Vps34p phosphatidylinositol-3-kinase complex \\
\hline YML052W & SUR7 & No & Plasma membrane component of eisosomes \\
\hline YML082W & & Yes & Protein of unknown function \\
\hline YMR032W & HOF1 & No & Regulates actin cytoskeleton organization \\
\hline YNL051W & COG5 & No & Conserved oligomeric Golgi complex subunit \\
\hline YNL058C & & No & Putative protein of unknown function \\
\hline YNL082W & PMS1 & Yes & ATP-binding protein required for mismatch repair \\
\hline YNL227C & JJJ1 & No & Stimulates the ATPase activity of Ssa1p \\
\hline YNL272C & SEC2 & No & Guanyl-exchange factor for small G-protein Sec4p \\
\hline YNL323W & LEM3 & Yes & Beta-subunit of Lem3p flippase \\
\hline YNR047W & FPK1 & No & Ser/Thr protein kinase activating Dnf2p \\
\hline YNR049C & MSO1 & No & Lipid-interacting protein in SNARE assembly \\
\hline YOL018C & TLG2 & Yes & Syntaxin-like t-SNARE \\
\hline YOL107W & & No & Putative protein of unknown function \\
\hline
\end{tabular}




\begin{tabular}{llll}
\hline YOR311C & DGK1 & No & Diacylglycerol kinase \\
\hline YPL001W & HAT1 & No & Hat1p-Hat2p histone acetyltransferase complex \\
\hline YPL028W & ERG10 & No & Acetyl-CoA C-acetyltransferase \\
\hline YPR089W & & No & Protein of unknown function \\
\hline YPR117W & & No & Putative protein of unknown function \\
\hline YPR151C & SUE1 & No & Degradation of unstable forms of cytochrome c \\
\hline
\end{tabular}

Table 1: List of genes identified in the miltefosine-resistance screen. Genes are listed in order of chromosomal position as noted from the standard SGD identifier, with gene name (if available), assessment of whether the mutant had previously been identified as resistant to edelfosine or miltefosine, and a description of the gene product. 
bioRxiv preprint doi: https://doi.org/10.1101/2020.10.16.343244; this version posted October 17,2020 . The copyright holder for this preprint (which was not certified by peer review) is the author/funder, who has granted bioRxiv a license to display the preprint in perpetuity. It is made available under aCC-BY 4.0 International license.

\begin{tabular}{|c|c|c|c|c|c|}
\hline GO identifier & GO Component $(\mathrm{C})$ or Process (P) & $\begin{array}{c}\text { Total for } \\
\text { term }\end{array}$ & Identified & $\begin{array}{r}\text { Fold } \\
\text { enrichme }\end{array}$ & p-value \\
\hline GO:0005794 & C:Golgi apparatus & 214 & 17 & 8.2 & $6.92 \mathrm{E}-12$ \\
\hline GO:0000139 & C:Golgi membrane & 121 & 10 & 8.5 & 1.77E-07 \\
\hline GO:0031201 & C:SNARE complex & 25 & 5 & 20.7 & 3.26E-06 \\
\hline GO:0005768 & C:endosome & 114 & 8 & 7.2 & 1.16E-05 \\
\hline GO:0016020 & C:membrane & 1718 & 31 & 1.9 & 5.54E-05 \\
\hline GO:0010008 & C:endosome membrane & 59 & 5 & 8.8 & 0.0002392 \\
\hline GO:0000938 & C:GARP complex & 4 & 2 & 51.6 & 0.0005458 \\
\hline GO:0034272 & $\begin{array}{l}\text { C:phosphatidylinositol 3-kinase } \\
\text { complex II }\end{array}$ & 4 & 2 & 51.6 & 0.0005458 \\
\hline GO:0030906 & C:retromer complex, inner shell & 4 & 2 & 51.6 & 0.0005458 \\
\hline GO:0030904 & C:retromer complex & 5 & 2 & 41.3 & 0.0009041 \\
\hline GO:0006810 & P:transport & 793 & 22 & 2.9 & $1.74 \mathrm{E}-06$ \\
\hline GO:0015031 & P:protein transport & 389 & 17 & 4.5 & $7.43 \mathrm{E}-08$ \\
\hline GO:0016192 & P:vesicle-mediated transport & 140 & 10 & 7.4 & $6.98 \mathrm{E}-07$ \\
\hline GO:0006897 & P:endocytosis & 88 & 8 & 9.4 & 1.64E-06 \\
\hline GO:0006896 & $\mathrm{P}:$ Golgi to vacuole transport & 24 & 5 & 21.5 & 2.63E-06 \\
\hline GO:0006623 & P:protein targeting to vacuole & 48 & 5 & 10.8 & 8.87E-05 \\
\hline GO:0042147 & $\begin{array}{l}\text { P:retrograde transport, endosome to } \\
\text { Golgi }\end{array}$ & 19 & 5 & 27.2 & 7.46E-07 \\
\hline GO:0006914 & P:autophagy & 51 & 4 & 8.1 & 0.001407 \\
\hline GO:0032258 & P:CVT pathway & 38 & 4 & 10.9 & 0.0004564 \\
\hline GO:0006906 & P:vesicle fusion & 20 & 4 & 20.7 & $3.41 \mathrm{E}-05$ \\
\hline GO:0006895 & P:Golgi to endosome transport & 14 & 3 & 22.1 & 0.0002905 \\
\hline GO:0006869 & P:lipid transport & 21 & 3 & 14.8 & 0.001012 \\
\hline GO:0045053 & P:protein retention in Golgi apparatus & 11 & 3 & 28.2 & 0.0001344 \\
\hline GO:0000011 & P:vacuole inheritance & 18 & 3 & 17.2 & 0.0006335 \\
\hline GO:0006904 & $\begin{array}{l}\text { P:vesicle docking involved in } \\
\text { exocytosis }\end{array}$ & 10 & 3 & 31.0 & 9.84E-05 \\
\hline GO:0048017 & P:inositol lipid-mediated signaling & 5 & 2 & 41.3 & 0.0009041 \\
\hline GO:0060988 & P:lipid tube assembly & 3 & 2 & 68.9 & 0.0002746 \\
\hline
\end{tabular}


bioRxiv preprint doi: https://doi.org/10.1101/2020.10.16.343244; this version posted October 17, 2020. The copyright holder for this preprint

(which was not certified by peer review) is the author/funder, who has granted bioRxiv a license to display the preprint in perpetuity. It is made available under aCC-BY 4.0 International license.

Table 2: Gene-ontology term enrichment. Genes identified in the mutant screen were analyzed with Gene Ontology (GO) based gene-set enrichment analysis tools available at www.yeastgenome.org. p-values were calculated based on the hypergeometric test, and GO terms with $p<0.005$ are included in the table. 
Acknowledgments: This work was supported by UNL Undergraduate Creative Activities and Research Enhancement (UNL-UCARE) and Ronald E. McNair Scholars program fellowships (to J.E.G.); National Science Foundation grant EPS-1004094 (to W.R.R.) and an Institutional Research Grant from the Fred and Pamela Buffett Cancer Center and the American Cancer Society (to W.R.R.) We thank Christopher Beh (Simon Fraser University, Vancouver, BC, Canada) and Tim Levine (University College London, London, UK) for providing yeast strains and plasmids as noted in the text.

Author contributions: J.E.G. acquired funding, performed research, assisted with study design, performed data analysis, prepared figures, and provided feedback on the manuscript draft; M.J.S performed research, assisted with data analysis, and provided feedback on the manuscript draft; D.R.V. provided space and assistance for generating the conceptual framework that led to this study, and provided feedback on early stages of study design and on the manuscript draft; W.R.R. designed the study, acquired funding, performed and directed research, and wrote the manuscript.

Conflict of interest statement: The authors declare no personal or financial conflicts of interest, and affirm that this work was conducted without interference or influence from the agencies that funded the work. 


\section{References:}

Aichelburg, A. C., J. Walochnik, O. Assadian, H. Prosch, A. Steuer et al., (2008) Successful treatment of disseminated Acanthamoeba sp. infection with miltefosine. Emerg. Infect. Dis. 14: 1743-1746.

Baird, D., C. Stefan, A. Audhya, S. Weys, and S. D. Emr, (2008) Assembly of the Ptdlns 4-kinase Stt4 complex at the plasma membrane requires Ypp1 and Efr3. J. Cell Biol. 183: 1061-1074.

Baker-Brachmann, C., A. Davies, G. J. Cost, E. Caputo, J. Li et al., (1998) Designer deletion strains derived from Saccharomyces cerevisiae. Yeast 14: 115-132.

Beh, C. T., L. Cool, J. Phillips, J. Rine, A. Adams et al., (2001) Overlapping functions of the yeast oxysterol-binding protein homologues. Genetics 157: 1117-40.

Cuesta-Marbán, Á., J. Botet, O. Czyz, L. M. Cacharro, C. Gajate et al., (2013) Drug uptake, lipid rafts, and vesicle trafficking modulate resistance to an anticancer lysophosphatidylcholine analogue in yeast. J. Biol. Chem. 288: 8405-8418.

Cutler, N. S., J. Heitman, and M. E. Cardenas, (1997) STT4 is an essential phosphatidylinositol 4-kinase that is a target of wortmannin in Saccharomyces cerevisiae. J. Biol. Chem. 272: 27671-27677.

Czyz, O., T. Bitew, A. Cuesta-Marbán, C. R. McMaster, F. Mollinedo et al., (2013) Alteration of plasma membrane organization by an anticancer lysophosphatidylcholine analogue induces intracellular acidification and internalization of plasma membrane transporters in yeast. J. Biol. Chem. 288: 8419-8432.

Foti, M., A. Audhya, and S. D. Emr, (2001) Sac1 lipid phosphatase and Stt4 phosphatidylinositol 4-kinase regulate a pool of phosphatidylinositol 4-phosphate that 
functions in the control of the actin cytoskeleton and vacuole morphology. Mol. Biol. Cell 12: $2396-411$.

Gajate, C., M. Matos-Da-Silva, E. L. H. Dakir, R. I. Fonteriz, J. Alvarez et al., (2012) Antitumor alkyl-lysophospholipid analog edelfosine induces apoptosis in pancreatic cancer by targeting endoplasmic reticulum. Oncogene 31: 2627-2639.

Gajate, C., and F. Mollinedo, (2014) Lipid Rafts, Endoplasmic Reticulum and Mitochondria in the Antitumor Action of the Alkylphospholipid Analog Edelfosine. Anticancer. Agents Med. Chem. 14: 509-527.

Guo, S., L. E. Stolz, S. M. Lemrow, and J. D. York, (1999) SAC1-like domains of yeast SAC1, INP52, and INP53 and of human synaptojanin encode polyphosphoinositide phosphatases. J. Biol. Chem. 274: 12990-12995.

Hanson, P. K., L. Malone, J. L. Birchmore, and J. W. Nichols, (2003) Lem3p is essential for the uptake and potency of alkylphosphocholine drugs, edelfosine and miltefosine. J. Biol. Chem. 278: 36041-36050.

Hughes, W. E., R. Woscholski, F. T. Cooke, R. S. Patrick, S. K. Dove et al., (2000) SAC1 encodes a regulated lipid phosphoinositide phosphatase, defects in which can be suppressed by the homologous Inp52p and Inp53p phosphatases. J. Biol. Chem. 275: 801-808.

Kaiser, S. E., J. H. Brickner, A. R. Reilein, T. D. Fenn, P. Walter et al., (2005) Structural basis of FFAT motif-mediated ER targeting. Structure 13: 1035-1045.

Kim, H., J. Shin, E. Kim, H. Kim, S. Hwang et al., (2014) YeastNet v3: A public database of data-specific and integrated functional gene networks for Saccharomyces cerevisiae. Nucleic Acids Res. 42:D731-D736. 
Loewen, C., and T. Levine, (2005) A highly conserved binding site in VAP for the FFAT motif of lipid binding proteins. J. Biol. Chem. 280: 14097-14104.

Loewen, C. J. R., A. Roy, and T. P. Levine, (2003) A conserved ER targeting motif in three families of lipid binding proteins and in Opi1p binds VAP. EMBO J. 22: 20252035.

Machado, P. R., J. Ampuero, L. H. Guimaraes, L. Villasboas, A. T. Rocha et al., (2010) Miltefosine in the treatment of cutaneous leishmaniasis caused by Leishmania braziliensis in Brazil: A randomized and controlled trial. PLoS Negl. Trop. Dis. 4: 1-6.

McGary, K. L., I. Lee, and E. M. Marcotte, (2007) Broad network-based predictability of Saccharomyces cerevisiae gene loss-of-function phenotypes. Genome Biol. 8:R258.

Mnaimneh, S., A. P. Davierwala, J. Haynes, J. Moffat, W. T. Peng et al., (2004) Exploration of essential gene functions via titratable promoter alleles. Cell 118: 31-44.

Pérez-Victoria, F. J., M. P. Sánchez-Cañete, S. Castanys, and F. Gamarro, (2006) Phospholipid translocation and miltefosine potency require both $L$. donovani miltefosine transporter and the new protein LdRos3 in Leishmania parasites. J. Biol. Chem. 281: $23766-23775$.

Riekhof, W. R., and D. R. Voelker, (2009) The yeast plasma membrane P4ATPases are major transporters for lysophospholipids. Biochim. Biophys. Acta - Mol. Cell Biol. Lipids 1791:620-627.

Riekhof, W. R., W.-I. Wu, J. L. Jones, M. Nikrad, M. M. Chan et al., (2014) An assembly of proteins and lipid domains regulates transport of phosphatidylserine to 
phosphatidylserine decarboxylase 2 in Saccharomyces cerevisiae. J. Biol. Chem. 289:5809-5819.

Rivas, M. P., B. G. Kearns, Z. Xie, S. Guo, M. C. Sekar et al., (1999) Pleiotropic alterations in lipid metabolism in yeast sac1 mutants: relationship to "bypass Sec14p" and inositol auxotrophy. Mol. Biol. Cell 10: 2235-50.

Roy, A., and T. P. Levine, (2004) Multiple pools of phosphatidylinositol 4phosphate detected using the pleckstrin homology domain of Osh2p. J. Biol. Chem. 279: 44683-44689.

Santa-Rita, R. M., A. Henriques-Pons, H. S. Barbosa, and S. L. de Castro, (2004) Effect of the lysophospholipid analogues edelfosine, ilmofosine and miltefosine against Leishmania amazonensis. J. Antimicrob. Chemother. 54: 704-710.

Saraiva, V. B., D. Gibaldi, J. O. Previato, L. Mendonça-Previato, M. T. Bozza et al., (2002) Proinflammatory and cytotoxic effects of hexadecylphosphocholine (miltefosine) against drug-resistant strains of Trypanosoma cruzi. Antimicrob. Agents Chemother. 46: 3472-3477.

Seifert, K., F. J. Pérez-Victoria, M. Stettler, M. P. Sánchez-Cañete, S. Castanys et al., (2007) Inactivation of the miltefosine transporter, LdMT, causes miltefosine resistance that is conferred to the amastigote stage of Leishmania donovani and persists in vivo. Int. J. Antimicrob. Agents 30: 229-235.

Tahirovic, S., M. Schorr, and P. Mayinger, (2005) Regulation of intracellular phosphatidylinositol-4-phosphate by the Sac1 lipid phosphatase. Traffic 6: 116-130.

Takagi, K., K. Iwamoto, S. Kobayashi, H. Horiuchi, R. Fukuda et al., (2012) Involvement of Golgi-associated retrograde protein complex in the recycling of the 
putative Dnf aminophospholipid flippases in yeast. Biochem. Biophys. Res. Commun. 417: 490-494.

Tani, M., and O. Kuge, (2014) Involvement of Sac1 phosphoinositide phosphatase in the metabolism of phosphatidylserine in the yeast Saccharomyces cerevisiae. Yeast 31: 145-158.

Trotter, P. J., W. I. Wu, J. Pedretti, R. Yates, and D. R. Voelker, (1998) A genetic screen for aminophospholipid transport mutants identifies the phosphatidylinositol 4kinase, Stt4p, as an essential component in phosphatidylserine metabolism. J. Biol. Chem. 273: 13189-13196.

Verma, N. K., G. Singh, and C. S. Dey, (2007) Miltefosine induces apoptosis in arsenite-resistant Leishmania donovani promastigotes through mitochondrial dysfunction. Exp. Parasitol. 116: 1-13.

Vila, T. V. M., A. K. Chaturvedi, S. Rozental, and J. L. Lopez-Ribot, (2015) Characterization of the in vitro activity of Miltefosine against Candida albicans under planktonic and biofilm growing conditions and in vivo efficacy in the murine model of oral candidiasis. Antimicrob. Agents Chemother. 59: 7611-7620.

Weingärtner, A., B. Drobot, A. Herrmann, M. P. Sánchez-Cañete, F. Gamarro et al., (2010) Disruption of the lipid-transporting Idmt-Idros3 complex in Leishmania donovani affects membrane lipid asymmetry but not host cell invasion. PLoS One 5:e12443.

Widmer, F., L. C. Wright, D. Obando, R. Handke, R. Ganendren et al., (2006) Hexadecylphosphocholine (miltefosine) has broad-spectrum fungicidal activity and is 
efficacious in a mouse model of cryptococcosis. Antimicrob. Agents Chemother. 50: 414421.

Wishart, J. A., A. Hayes, L. Wardleworth, N. Zhang, and S. G. Oliver, (2005) Doxycycline, the drug used to control the tet-regulatable promoter system, has no effect on global gene expression in Saccharomyces cerevisiae. Yeast 22: 565-569.

Yoshida, S., Y. Ohya, M. Goebl, A. Nakano, and Y. Anraku, (1994) A novel gene, STT4, encodes a phosphatidylinositol 4-kinase in the PKC1 protein kinase pathway of Saccharomyces cerevisiae. J. Biol. Chem. 269: 1166-1171. 

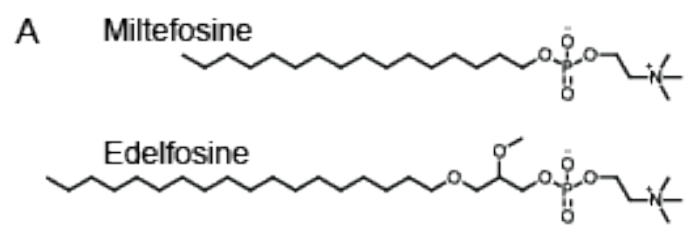

Lyso-phosphatidylcholine

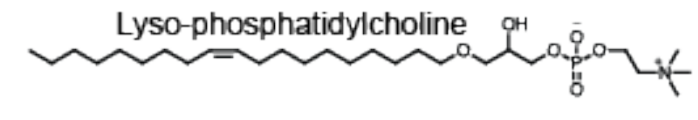

B

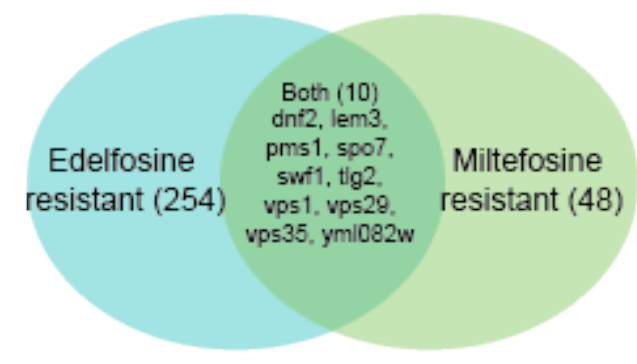

C

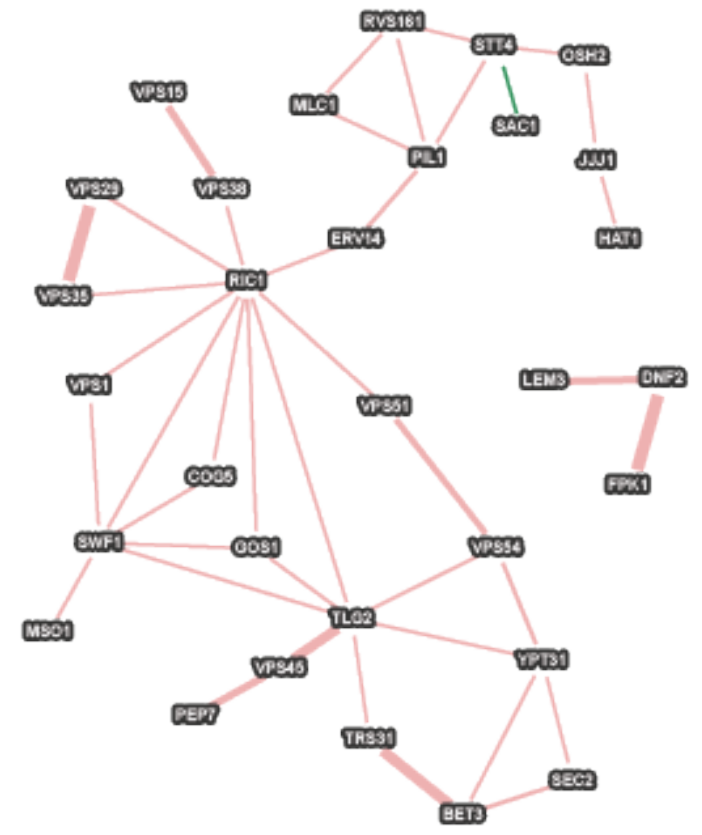

Garcia et al., 2020, Fig.1
Figure 1: Overlap between previous and current screens for APC resistance. A, Structures of alkylphosphocholine compounds discussed in the text in comparison with lysoPhosphatidylcholine.; $\mathrm{B}$, Venn diagram illustrating the limited overlap in gene sets between the current study and previous studies on edelfosine resistance.; $\mathrm{C}$, Physical and genetic interaction network of genes identified as being important for both miltefosine and edelfosine resistance, with additional network neighbors from the miltefosineonly screen described in this work. 


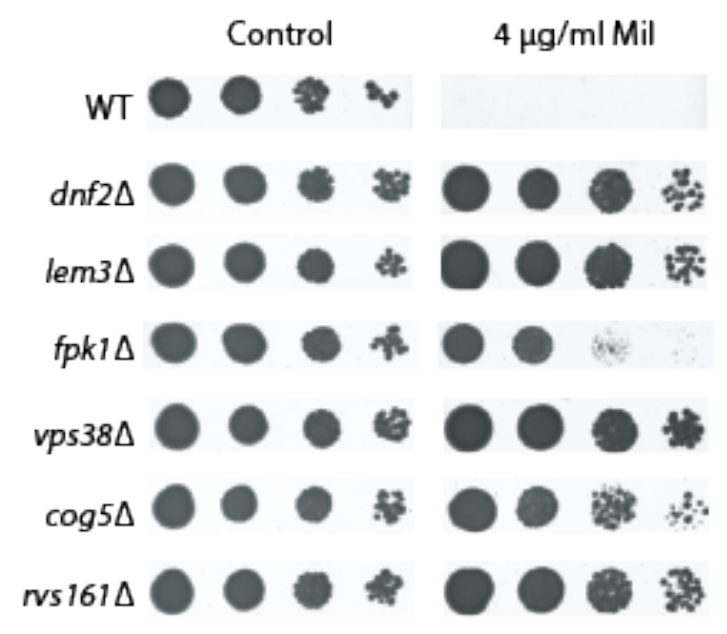

Garcia et al., 2020, Fig. 2
Figure 2: Miltefosine-resistance phenotypes. Primary screening led to the identification of strains with a range of resistance phenotypes. Strains were grown overnight in YPD and a 5-fold serial dilution series was prepared and pinned to solid YPD agar with or without miltefosine. Plates were photographed after 3 days. The densest spots correspond to the 1:25 dilution, and lightest correspond to $1: 3125$ dilution. A range of phenotypes from weakly (fpk1 $1 \Delta$ ) to modestly $(\operatorname{cog} 5 \Delta)$ to strongly (dnf2 $\Delta, \operatorname{vps} 38 \Delta$ ) resistant are noted. 


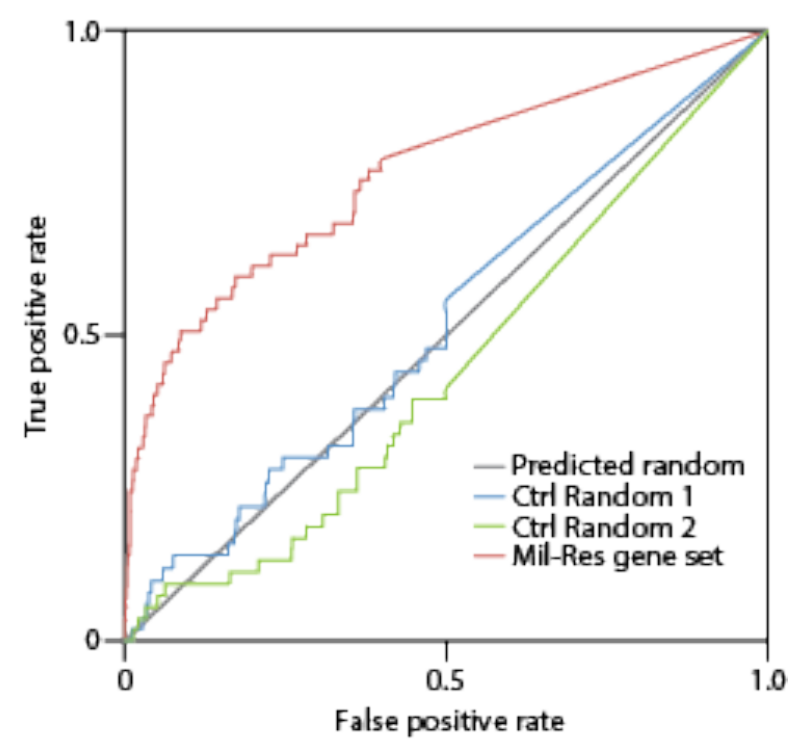

Garcia et al., 2020, Fig. 3
Figure 3: Receiver-operating characteristic curve analysis. The gene set of reproducibly miltefosine resistant mutants was analyzed with gene-set enrichment analysis tools from the YeastNet v3 package at https://www.inetbio.org/yeastnet/ as described in the text. Two sets of randomly selected genes were analysed for comparison, and the miltefosine-resistant gene set was found to identify genes that were significantly connected to each other via protein:protein interactions, genetic epistasis, shared domain architectures, and co-citation indices with an $E$ value of less than $1 \times 10^{-10}$. 


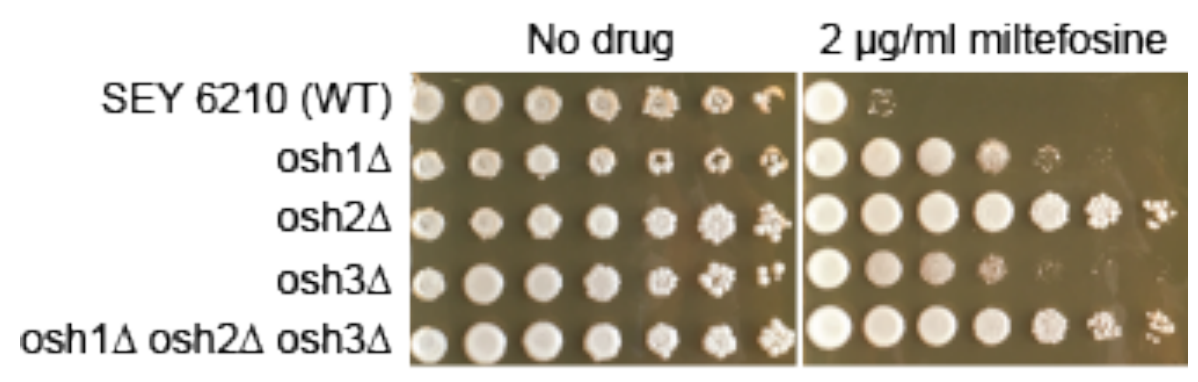

\section{Garcia et al., 2020, Fig. 4}

Figure 4: Oxysterol binding protein homologs are necessary for wild-type miltefosine sensitivity. An osh $2 \Delta$ strain was identified in the primary screen conducted in the BY4742 background. To confirm the role of Osh2p and its orthologs Osh1p and Osh $3 p$ and determine whether there were background specific differences in sensitivity, we assessed the growth of strain SEY6210 and isogenic osh $1 \Delta$, osh2 $2 \Delta$, osh2 $\Delta$, and the triple mutant. Overnight cultures were subjected to 5 -fold serial dilution and pinned to solid media as described in the text. 


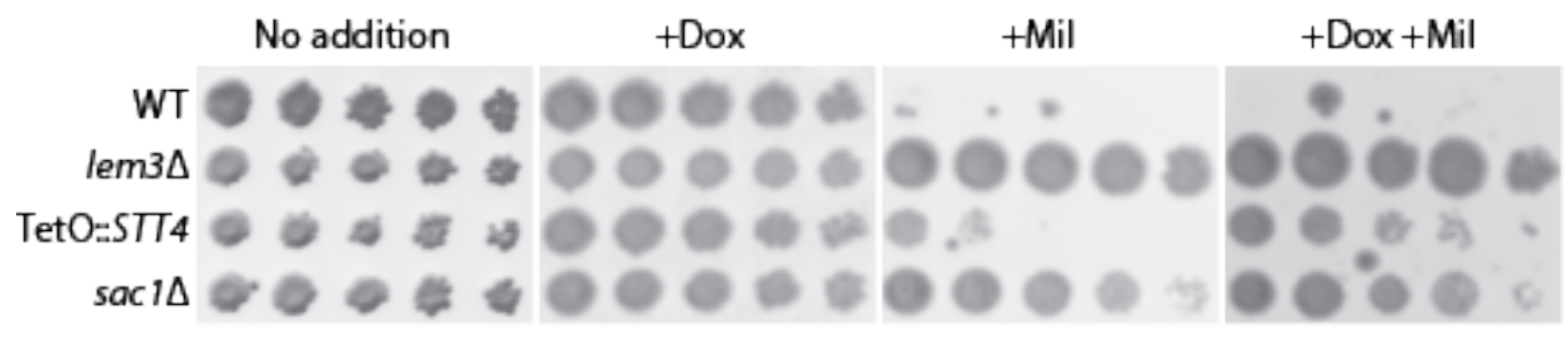

\section{Garcia et al., 2020, Fig. 5}

Figure 5: The phosphatidylinositol-4-kinase/phosphatase cycle is a determinant of miltefosine sensitivity. The essential gene STT4, encoding the major Ptdlns-4-kinase isoform in yeast, was identified in the essential-titratable gene collection. Inhibition of STT4 expression by including doxycycline in the growth media $(10 \mu \mathrm{M})$ led to mitefosine resistance $(4 \mu \mathrm{g} / \mathrm{ml}$.) The Ptdlns-4-P phosphatase Sac1p, was also identified and a sac1 $\Delta$ strain was included in this series, and lem $3 \Delta$ was included as a previously characterized miltefosine resistant positive control. 5fold serial dilutions were prepared and pinned to solid media as described in the text. 

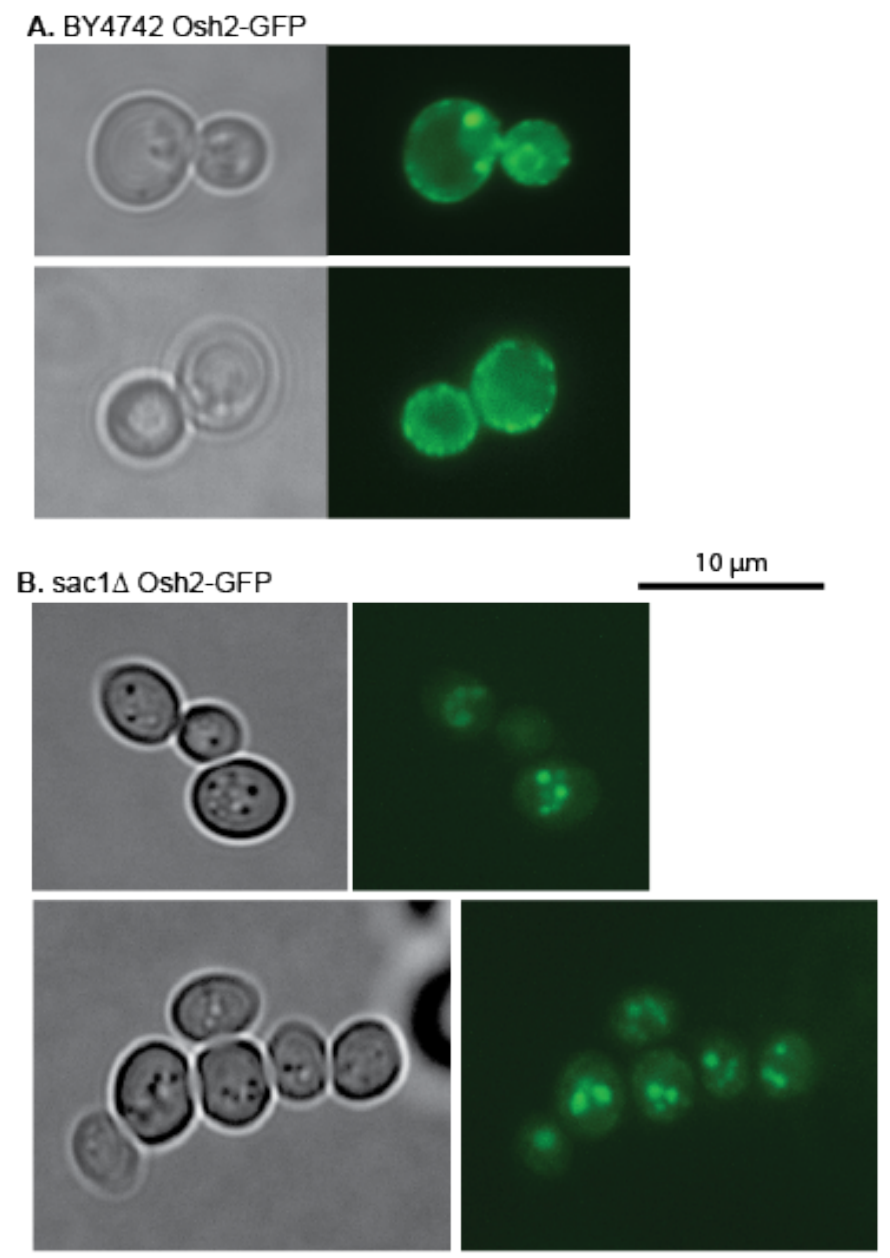

Garcia et al., 2020, Fig. 6

Figure 6: Osh2p is mislocalized in a sac1 $\Delta$ mutant background. Osh2-GFP expressed from a URA3 CEN plasmid under its native promoter was introduced into the BY4742 wild type and isogenic sac $1 \Delta$ mutant strains. Strains were grown in SC -Ura media overnight and images were acquired on an Evos-FI inverted microscope with a GFP light cube using a 100x oil-immersion objective. 